\title{
A PERSPECTIVA SOCIOANTROPOLÓGICA DE MUNDICARMO FERRETTI SOBRE A MÚSICA REGIONAL DE ZEDANTAS E LUIZ GONZAGA
}

\section{THE SOCIO ANTROPOLOGICAL PERSPECTIVE OF MUNDICARMO FERRETTI ON REGIONAL MUSIC OF ZEDANTAS AND LUIZ GONZAGA}

\author{
João Paulo Guedes*
}

FERRETTI, Mundicarmo. Na batida do Baião, no balanço do Forró: Zedantas e Luiz Gonzaga. Recife: Fundação Joaquim Nabuco, Editora Massagana, 2012. 232 p.

Apresentado em 1983, curiosamente no ano de nascimento do autor desta resenha linhas, inicialmente como dissertação de mestrado em Ciências Sociais pela UFRN, tornou-se um livro publicado em três edições: $1988^{1}, 2007^{2}$ e $2012^{3}$. A última edição - um livro feito em homenagem ao centenário de nascimento de Luiz Gonzaga Na batida do Baião, no balanço do Forró: Zedantas e Luiz Gonzaga, da antropóloga Mundicarmo Ferretti, traz informações valiosas sobre o repertório desses dois artistas, o contexto de produção da obra e sua atualização no cenário musical décadas depois. Entendendo a música como fator determinante em uma cultura, capaz de congregar diversas linguagens, como o jeito de falar, poesia, ditados e provérbios, percepções rítmicas e melódicas da cultura de uma região (no caso, o sertanejo nordestino), a autora tem como objetivo, nessa obra, identificar a integração da música nordestina na comunicação de massa (rádios, discos e forrós), avaliando os fatores que propiciaram a uma

* É graduado em Ciências Sociais pela PUC Campinas; Mestrando em Ciências Sociais pela UFMA (São Luis/MA/Brasil), sob orientação do Prof. Dr. Sérgio Figueiredo Ferretti; membro do Grupo de Pesquisa Religião e Cultura Popular - GPMINA, vinculado à UFMA; percussionista e professor de música na rede de ensino de São Luís/MA.joaopaulo_guedes@yahoo.com.br.

1. Editora Massagana - $1^{\text {a }}$ edição.

2. Companhia Editora de Pernambuco - 2a edição.

3. Editora Massagana - $3^{\text {a }}$ edição. 
produção cultural marginal tornar-se divulgada e consumida nacionalmente. A autora segue com uma análise da atualização dessa música, isto é, de sua retomada por artistas de uma geração posterior, que (re) colocaram, com a força de antes, a música nordestina no cenário musical brasileiro e internacional a partir da década de 1970, embora com outra roupagem. Analisa principalmente a obra da parceria dos pernambucanos Luiz Gonzaga e Zedantas no seu contexto de produção, emissão e recepção, além de aspectos literários e musicais.

No primeiro capítulo, Ferretti faz uma análise da Arte em suas condições de pro$d u c ̧ a \tilde{a} o^{4}$ e retoma uma tradição de cientistas sociais que teorizaram sobre a arte popular, a comunicação de massa e suas relações de poder como Canclini e Gramsci, situando um campo em que atuam compositores, músicos, intérpretes, produtores, arranjadores e outros profissionais ligados à indústria cultural e à relação entre produção e mercado consumidor. Ao optar pela orientação socioeconômica de Canclini, ao invés de entender a arte como ideologia, procura a relação entre arte e sociedade, na qual a criação artística vincula-se às condições materiais de produção, ou seja, à inserção do artista em instituições e formas de organização que condicionam suas produções e que possuem um objetivo muito específico: a venda de discos e produções que envolvam um maior lucro para a indústria cultural. Para tanto, propõe um modelo que não é focado exclusivamente no autor ou na obra, mas no processo artístico integrado: artista, obra, intermediários, instituições e público. Para a autora, não se pode analisar a música ou a letra separadamente, como ocorreram com alguns estudos da
MPB (Música Popular Brasileira) da década de 1960. É preciso levar em consideração os vários códigos expressos na produção e recepção para a transmissão da mensagem, visto que o ritmo pode, por exemplo, muitas vezes ser mais importante que a letra.

Enveredando-se pela inspiração de Gramsci, Ferretti não considera a música popular tradicional como algo preso em um tempo distante, que só faz sentido no passado. Ao contrário, propõe a dimensão histórica da música tradicional ao entender que o momento histórico não é homogêneo, mas fruto de representações. 0 tradicional é entendido como atual e reflete a realidade vivida "aqui e agora”. Caso a música não varie, varia o seu significado quando em outros contextos de recepção. É o caso da música que tem seu sentido percebido de modo distinto por públicos diferentes quando executada em festas de forró do Nordeste, onde o público é sertanejo, ou em Casas de Forró que, num outro momento, aderem citadinos membros da classe média.

Pode-se dizer que o baião - síntese de elementos da música e poética de diversos estados nordestinos, estilizado para atender a um público maior e diversificado, porém sempre com um caráter regionalista em seu ritmo e temas que remetem à vida ao mesmo tempo árdua e alegre do sertanejo nordestino - foi criado e lançado na comunicação de massa em 1946, quando foi gravada, pelo grupo Quatro Ases e um Coringa, a música Baião (1945), de parceria entre Luiz Gonzaga e o cearense Humberto Teixeira. Leonardo Dantas Silva, no prefácio da primeira edição da obra de Ferretti (1988), ao fazer uma análise musicológica, define o baião como fruto da

4. Os nomes dos capítulos estão em itálico. 
(...) união do dedilhado da viola, que antecipa o desafio do cantador nordestino, apelidado de baiano, com a cantiga tonal de origem medieval encontrada nas toadas dos cegos de feira do Nordeste brasileiro; à reunião desses ingredientes convencionou-se chamar de baião. (MUNDICARMO FERRETTI, 2012, p.10, grifos no original)

0 baião, com sua batida uniforme propícia para se dançar, utilizando-se de instrumentos adotados pela cultura nordestina - sanfona, triângulo e zabumba - e incorporando a temática a sons de forrós nordestinos como gritos, interjeições e declamações características desses espaços, lança, portanto, o Nordeste no cenário musical brasileiro. Resumidamente, o baião teve sua fase áurea entre os anos de 1949 e 1954, quando se tornou ritmo da moda a nível nacional através da difusão de Luiz Gonzaga cantando músicas em parceria com Humberto e Teixeira e Zedantas. Entre 1954 e 1960, o baião entra em ostracismo na comunicação de massa, apesar de continuar vivo nas residências de nordestinos erradicados nos subúrbios das grandes cidades, e após 1972 é retomado por artistas de uma nova geração de nordestinos, entre eles, Caetano Veloso e Gilberto Gil, bem como Alceu Valença, Fagner e Elba Ramalho, que cresceram e foram influenciados tanto musicalmente como poeticamente pela obra de Luiz Gonzaga, Humberto Teixeira e Zedantas. Nessa época, o gênero nordestino agrega também a juventude da classe média e universitária que se reunia para divertir-se nas Casas de Forró, ao som de antigos sucessos cantados por Luiz Gonzaga.

Apesar de poucas informações, e praticamente nenhum trabalho acadêmico publicado sobre A música de Luiz Gonzaga e Zedantas, Ferretti recorreu a diversos ar- tigos de poetas, folcloristas, historiadores e críticos da música popular, jornalistas, encartes de discos e entrevistas. Segundo a autora, grande parte das informações obtidas tinha o viés principal das interpretações de Luiz Gonzaga e Humberto Teixeira, sendo necessária uma análise da produção de Zadantas. A visão de Zedantas foi colhida em arquivos de sua família e por meio de entrevistas com pessoas próximas a ele.

Ao analisar A música popular e identidade regional - o gênero nordestino como fruto da inserção da música tradicional carregada de elementos significativos da cultura nordestina na comunicação de massa, e como forma de expressão capaz de influenciar artistas das regiões mais ricas do país, Ferretti reitera um ponto de vista expresso por T. Souza (ibid., p. 47), para quem o que houve com o baião foi uma espécie de "colonização ao contrário", isto é, uma forte influência da cultura marginalizada na cultura hegemônica. Com isso, a autora utiliza-se da análise de Umberto Eco para definir uma imposição de um ethos popular da comunicação de massa.

Parece que é justamente este tom, caráter ou qualidade da vida sertaneja - vale lembrar que não em termos substanciais, essenciais, mas como construções culturais - que são expressos na estética (ritmo, melodias, vestimenta, etc.) do baião e revelam sua moral (árduo, alegre, valente, com fé, etc.). 0 baião, mesmo que alguns critiquemno enquanto uma estilização que descaracteriza ou higieniza a cultura do povo, impõe seu ethos a uma gama de receptores muito distantes da realidade do sertão nordestino. Com certeza o foi para o autor destas linhas, que, advindo de uma realidade completamente diferente das cantadas nas canções de Luiz Gonzaga, pôde perceber, ainda que superficialmente, as tristezas da seca 
e da fome, a alegria da chegada da chuva e da fartura e, principalmente, a musicalidade e poética do sertanejo nordestino em uma linguagem que não o pertencia. Essa é a força que uma música popular - definida por Ferretti como aquela produzida ou adotada pelas camadas de baixa renda e que a acompanha em seu cotidiano ${ }^{5}$ - exerce ao romper fronteiras locais e espalhar-se para ouvidos e corações distantes.

Obviamente, existem diversos condicionantes da indústria cultural nesse processo, como bem observa a autora. Porém, a amplitude que tomou a imposição desse ethos popular na cultura de massa com certeza alterou significativamente o olhar para a região do Nordeste brasileiro. Ao fazer um protesto reivindicatório muito mais para a visibilidade dos problemas do Nordeste do que de oposição ou enfrentamento político, a música de Luiz Gonzaga com Zedantas procurava devolver o sentimento de dignidade ao povo nordestino, que fora estigmatizado nas regiões mais ricas do país. Isso a caracteriza como música regional - que não é nem urbana, nem rural e nem nacional.

A música nordestina e sua vinculação à comunicação de massa, bem como sua difusão a nível nacional, foi possível por um viés da política populista da era Vargas unida à popularização da comunicação radiofônica, que abria espaços para artistas das classes baixas por terem um grande público ouvinte e mercado em potencial, como nos mostra a autora. Com o nacionalismo propagado por aquela política, o baião era tido como resistência à cultura estrangeira, principalmente como contraponto à popularização do rock americano e britânico. Além disso, aproximou o trabalho do sertanejo agrícola da perspectiva de desenvolvimento nacional, como na música Algodão, encomendada pelo governo à dupla Luiz Gonzaga e Zedantas, que trata, entre outras questões, de incentivar a produção de algodão "que tanto enriquece nosso país".

Através de intensas mudanças provocadas pela televisão e pela aceitação e grande popularização de músicas estrangeiras, o baião sai de moda em meados da década de 1950. Há também um crescente interesse no elitismo e sofisticação da Jovem Guarda e da Bossa Nova, bem adequada ao tecnicismo e desenvolvimentismo propagados pela política de Juscelino Kubitschek, onde a música do povo era vista como atrasada, precária. A partir dos anos 1960, o gosto musical passa a refletir patentemente a divisão de classes. De um lado a elite, apreciando a MPB difundida pela indústria cultural, e do outro a música "do povo", tradicional, na qual estava enquadrado o baião. No fim da década de 1960 e começo dos anos 1970, o movimento Tropicalista que, entre outras medidas, pretendia colocar em evidência a interpenetração cultural através da comunicação de massa, misturando elementos modernos da elite, como o rock, a elementos tradicionais do povo, como o baião, assim deglutindo esteticamente a cultura estrangeira, coloca novamente em cena a música de Luiz Gonzaga, apesar da severa repressão pelo regime ditatorial e crescente "invasão" da música estrangeira.

Em 1972 Luiz Gonzaga volta ao cenário musical em show no Rio de Janeiro inti-

5. Parece que esta é a definição adotada pela autora. Porém, considera-se o termo música popular ambíguo pela maneira com que esta é tratada pela indústria cultural e por pesquisadores quando consideram música popular também aquelas produzidas pelas classes mais altas com uma amplitude popular, de massa, como no caso de Chico Buarque, Rita Lee, etc. 
tulado "Luiz Gonzaga volta para curtir", que confirma sua aceitação por um público diferente, agora universitário e de classe média, trazendo elementos antes ignorados em sua música, como a guitarra elétrica, em conjunto com a tradicional sanfona, a zabumba e o triângulo. Essa aceitação foi concretizada juntamente com a criação de Casas de Forró que apareciam enquanto alternativa às saturadas discothéques para jovens universitários.

Ferretti nos mostra como $O$ encontro do intelectual com o artista do povo na comunicação de massa - Luiz Gonzaga e Zedantas também possibilitou a integração da música nordestina na indústria cultural, que mantinha uma série de preconceitos em relação ao povo nordestino e suas expressões culturais. Preconceito esse também presente entre produtores e consumidores que viam tal cultura como inferior. Neste capítulo, a autora mostra o papel de intelectuais da elite nordestina, como Humberto Teixeira e Zedantas, na mediação entre cultura popular e indústria cultural, contribuindo para a sua integração e quebra de preconceitos. Portanto, através da leitura da cultura popular por compositores de classe média em conjunto com um artista do povo, tornou possível que um sanfoneiro popular se tornasse o "Rei do Baião". A isso, soma-se a vasta experiência musical de Luiz Gonzaga vinda de sua família, de sua vivência no exército em Fortaleza e de sua residência no Rio de Janeiro, lugares em que pôde ampliar seu repertório musical, com músicas feitas para jazz band, polcas paraguaias, tangos, valsas, sambas, gafieiras, etc, que seriam (re)interpretadas de diferentes maneiras em sua obra.

Apesar de sua origem elitista, o médico Zedantas apresentava fascínio pela vida no sertão nordestino, onde buscava inspiração ao frequentar forrós "pé de serra" em suas férias. Porém, em suas representações, fazia certas adaptações ao gosto do homem citadino, o que é analisado por Ferretti como uma "reelaboração do folclore" (ibid., p. 96). Na análise da autora, sempre está viva a ideia de que o tradicional não está preso ao passado, e sim atualizado no presente, o que se dá pela habilidade conjunta de reelaboração cultural e zelo pelas tradições de Luiz Gonzaga e Zedantas.

No penúltimo capítulo, Uma reelaboração do folclore que não se cristalizou - a música de Zedantas e Luiz Gonzaga, a autora analisa o modo com que estes autores trabalharam o folclore nordestino e enfatiza a temática desenvolvida por Zedantas - a qual atribui como motivos principais, a "tristeza da seca e a alegria do inverno" - e sua atualização em discos e shows de Luiz Gonzaga após seu falecimento. Ferretti ,mostra uma visão geral do repertório de Zedantas, citando inclusive outros parceiros e intérpretes e pesquisando sua produção em diversas fontes. Apesar de genericamente chamado de baião, grande parte do repertório desses dois artistas constitui-se de toadas, xotes e ritmos tradicionais como maracatu, xaxado, ritmos juninos e cocos, todos adaptados pelo intérprete em sua estilização em um trabalho tanto de divulgação e de adaptação do folclore como de criação artística. Além da musicalidade, a poética também é analisada criteriosamente pela autora nas letras das canções e mostra grande influência da literatura oral do folclore nordestino, dos sons da natureza, dos trabalhos do sertão, dos forrós e de outros elementos que compõem o ethos nordestino presente na obra desses autores. Apesar da música desses compositores aparecer para alguns como resistente a mudanças, a autora nos mostra as adaptações por que pas- 
saram, dependendo das exigências de cada época, culminando em mudanças mais claras a partir da década de 1970 com a adesão da classe média universitária e proliferação das Casas de Forró. Em cada nova configuração, muitos sucessos foram regravados de forma diferente e interpretados de maneira diferente, como alerta Ferretti:

Para se compreender o sentido atribuído por um grupo a uma determinada música, é necessário que se analise também a situação em que foi apresentada e os objetivos pretendidos pelos seus usuários. (ibid., p. 147).

A autora conclui ao afirmar que a música de Zedantas com Luiz Gonzaga, produzida para ampla difusão a partir do folclore nordestino e consumida sobretudo pelas camadas de baixa renda da população urbana, "reflete um momento histórico vivido pela sociedade brasileira e as condições específicas de produção da MPB na década de 1950". (ibid., p. 150). Trata-se de uma obra com importantes análises sociológicas e antropológicas sobre a música nordestina nas décadas compreendidas entre 1940 e final da década de 1970.

Recebido em: 22/04/15

Aprovado em: 15/06/15 